\title{
Prevalence of vitamin D deficiency and effect of vitamin D supplementation on feto-maternal outcome in tertiary care centre
}

\author{
Munmun Yadavi, Mahendra Kumar Verma ${ }^{2 *}$, Mohan Bairwa ${ }^{3}$, \\ Govardhan Meena ${ }^{4}$, Lata Rajoria ${ }^{5}$
}

\begin{abstract}
${ }^{1}$ Department of Obstetrics and Gynecology, ${ }^{2}$ Department of Community Medicine, SMS Medical College and Attached Hospitals, Jaipur, Rajasthan, India

${ }^{3}$ Department of Public Health and Epidemiology, IIHMR University, Jaipur, Rajasthan, India

${ }^{4}$ Department of Community Medicine, Shri Kalyan Govt Medical College and Hospital, Sikar, Rajasthan, India

${ }^{5}$ Department of Obstetrics and Gynecology, Zanana Hospital, Jaipur, Rajasthan, India
\end{abstract}

Received: 13 September 2018

Accepted: 06 October 2018

\section{*Correspondence:}

Dr. Mahendra Kumar Verma,

E-mail: drmahendraverma@outlook.com

Copyright: (c) the author(s), publisher and licensee Medip Academy. This is an open-access article distributed under the terms of the Creative Commons Attribution Non-Commercial License, which permits unrestricted non-commercial use, distribution, and reproduction in any medium, provided the original work is properly cited.

\section{ABSTRACT}

Background: Vitamin D deficiency is widely prevalent throughout the world. Pregnant women, neonates and infants form most vulnerable groups for vitamin D deficiency. Hypovitaminosis D in pregnancy has been reported to cause various fetomaternal effect, i.e. increased risk of preeclampsia (PE), gestational diabetes mellitus (GDM), caesarean section, hypocalcemia, subclinical myopathy, neonatal tetany, hyperbilirubinemia congenital rickets and infantile rickets, etc. Only few Indian studies are available in this regard. The objectives are to find prevalence of vitamin D deficiency in pregnant women and to evaluate the effect of supplementation with cholecalciferol in improving vitamin $\mathrm{D}$ levels in pregnant women and evaluate its correlation with feto-maternal outcome.

Methods: A prospective observational was conducted on 120 Pregnant women on their first visit to hospital irrespective of gestational age were offered the test and on the basis of inclusion and exclusion criteria are included in study and vitamin D level was done to know the prevalence of vitamin D deficiency. Apart from routine obstetrical investigation, serum vitamin D (total) level was estimated. All results were recorded and analyzed statically.

Results: Out of 120 patients $101(84.1 \%)$ were found to be vitamin D deficient. Mean age of vitamin D deficient group was $28.31 \pm 3.86$ and sufficient group was $26.37 \pm 2.83 .81(67.5 \%)$ were vegetarian and $39(32.5 \%)$ were nonvegetarian.75 (92.59\%) vegetarian and $26(66.66 \%)$ non-vegetarian found to be vitamin D deficient. $(\mathrm{p}<0.05)$. Vitamin D supplementation has been observed to reduce risk of preeclampsia. $(\mathrm{p}<0.05)$ and vitamin D sufficiency associated with reduced risk of low birth weight babies.

Conclusions: Vitamin D supplementation reduces risk of maternal comorbidities and helps improve neonatal outcomes.

Keywords: Feto-maternal outcome, Hypovitaminosis D, Vitamin D status in pregnancy, Maternal blood vitamin D

\section{INTRODUCTION}

Vitamin D, a lipid-soluble vitamin and prohormone, is known to play an important role in bone metabolism through regulation of calcium and phosphate homoeostasis. ${ }^{1}$ Vitamin D traditionally known as "antiricketic or sunshine vitamin".

It is a unique nutrient because it can be synthesized endogenously (skin) and it function as a hormone. ${ }^{2}$ 
Vitamin D deficiency is prevalent worldwide, and its unrecognized epidemic is common in all age groups ranging from $46-90 \% .^{3-9}$ Various Indian studies have reported vitamin D deficiency in all age groups and involving both sexes. Its prevalence ranging between 40 $93 \% .{ }^{10-12}$ During pregnancy high prevalence of vitamin D deficiency has been reported from various region of world, ranging from $45-100 \% .^{7-9}$ And in Indian population it has been reported to the tune of $42-93 \% .^{13-16}$

Studies regarding prevalence of vitamin D deficiency in antenatal women in India are mainly from Northern and southern India and very a few from central Part of India, thus this study has been undertaken in order to know the prevalence of vitamin D deficiency of antenatal women in present institute. ${ }^{13-16}$ Vitamin D functions in both classical and non-classical ways: The action of 1 , $25(\mathrm{OH})_{2} \mathrm{D}$ are mediated through specific, high affinity binding to the vitamin $\mathrm{D}$ receptor (VDR). The classical way to regulate calcium and phosphorus absorption and help in bone synthesis and metabolism via its action on kidney-liver- intestine. ${ }^{17}$ Recent data of non-classical way of function of Vitamin D is via the target organ in the endocrine system which include adaptive and immune system, $\beta$ - pancreatic cell, cardiovascular system and brain. $^{18}$

Vitamin D deficiency during pregnancy is associated with the non- classical action of this hormone, being linked with preeclampsia, insulin resistance, gestational diabetes mellitus, and risk of Caesarean section, impaired calcium metabolism and fetal growth. ${ }^{19-22}$

Studies reported in India are mainly from Northern and southern India and very a few from central Part of India, thus this study has been undertaken in order to know the prevalence and its maternal and fetal outcome in present institute.

\section{METHODS}

This study was a prospective observational study conducted in the Department of Obstetrics and Gynaecology in collaboration with the department of nuclear medicine of Jawahar Lal Nehru Hospital and Research Centre, Bhilai, Chhattisgarh, India, from October 2015 to November 2016 after approval from the hospital ethical committee.

\section{Inclusion criteria}

- Antenatal women on their first visit to hospital, irrespective of period of gestational age.

- Patient's willingness to get test done.

\section{Exclusion criteria}

- Patients on vitamin D supplementation in early pregnancy before attending ANC OPD/ IPD
- Patients with essential hypertension and known case of Diabetes mellitus.

Written informed consent was taken from patient or guardian/ relatives prior to enrolment in the study.

\section{Methodology}

Pregnant women (Antenatal women) on their first visit to hospital irrespective of gestational age were offered the test and on the basis of inclusion and exclusion criteria are included in study and vitamin D level was done to know the prevalence of vitamin D deficiency. Apart from routine obstetrical investigation, serum vitamin D level estimation was done by fully automated chemiluminescent immunoassay and radioimmunoassay (RIA).

Table 1: Reference range-recently revised institute of medicine's (IOM) criteria $2010 .^{23}$

\begin{tabular}{|lll|}
\hline & Vit D3 level & \\
& $\mathbf{n g} / \mathbf{m l}$ & $\mathbf{n m o l} / \mathbf{l}$ \\
\hline Vitamin D sufficiency & $>30$ & $75-80$ \\
\hline Vitamin D insufficiency & $21-29$ & $49-75$ \\
\hline Vitamin D deficiency & $<20$ & 50 \\
\hline
\end{tabular}

$1 \mathrm{nmol} / \mathrm{l}=0.4 \mathrm{ng} / \mathrm{ml}$

Antenatal women having vitamin D level below 30ng/ml were supplemented with 60,000 IU of cholecalciferol weekly. As vitamin D deficient women belonged to different period of gestation at the start of therapy hence, period of supplementation with vitamin D was variable. To achieve normalcy of vitamin D level 8 weeks of therapy is considered adequate, taking reference of study done by Malbanan and Goswami. ${ }^{24,25}$

For the study purpose all antenatal women will be divided in to two groups:

\section{Group 1 (vitamin D sufficient group)}

- Women with vitamin D level $\geq 30 \mathrm{ng} / \mathrm{ml}$ on first visit.

- Vitamin D deficient women who will be supplemented with $60,000 \mathrm{IU}$ of cholecalciferol weekly for 8 weeks to normalize their vitamin D level in sufficient range.

\section{Group 2 (vitamin D deficient group)}

- This group included antenatal women diagnosed with deficiency in late pregnancy where in spite of weekly supplementation with vitamin $\mathrm{D}$, duration of therapy was $<8$ weeks. Hence, these women were taken in deficient group.

Sample size: 120 cases.

Cochran formula for sample size for descriptive analysis, 
Equation: Sample size $N=\frac{1.96^{2} \times p \times(1-p)}{e^{2}}$

P - Percentage of pregnant women having vitamin D deficiency from a previous study $=72.1 \%=0.721$.

\section{Statistical analysis}

Data thus collected were entered in Microsoft Excel Sheet by investigator himself on same day so as to minimize data entry bias if any analysed using SPSS version 24. The results were presented as percentages and Chi-square test was used to assess the association. Pvalue of less than 0.05 was taken as the level of significance.

\section{RESULTS}

The present study was undertaken in order to determine the vitamin D level in 120 pregnant women, age range of 19-39 years with first visit to hospital irrespective of their gestational age. Out of these 101 cases $(84.1 \%)$ were found vitamin $\mathrm{D}$ deficient. The prevalence of vitamin $\mathrm{D}$ deficiency was found $84.1 \%$ or 841.66 per thousand women. The mean age of vitamin $\mathrm{D}$ deficient group was found $28.31 \pm 3.86$ years. The mean age of vitamin $D$ sufficient group was found $26.37 \pm 2.83$ years. Maximum number of patients were Hindu 114 (95\%) and out of this,
$97(85.08 \%)$ were vitamin D deficient and 17 (14.9\%) were vitamin D sufficient.

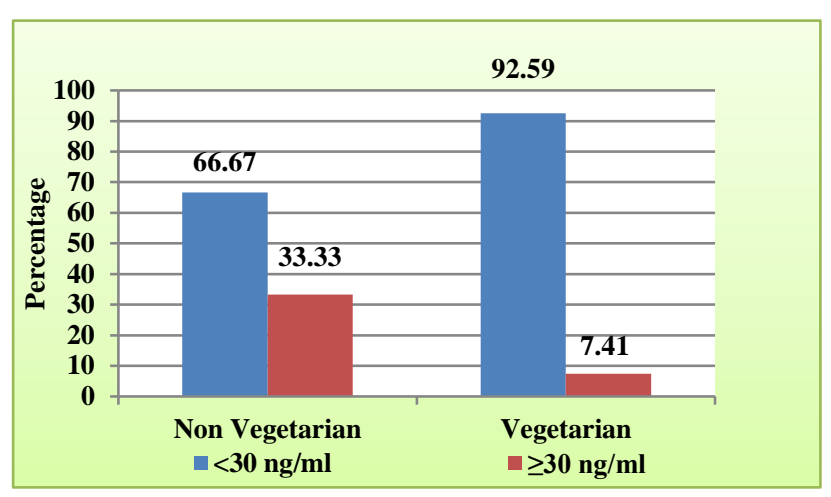

Figure 1: Distribution of cases according to diet.

Only $6(5 \%)$ cases were Muslim out of this $4(66.66 \%)$ were vitamin D deficient and $2(33.33 \%)$ were vitamin D sufficient. Maximum number $81(67.5 \%)$ patients were vegetarian, out of this $75(92.5 \%)$ were vitamin D deficient and only $6(31.58 \%)$ were vitamin D sufficient.39 patients were non-vegetarian, out of this 26 $(66.66 \%)$ were vitamin D deficient and $13(33.33 \%)$ were vitamin D sufficient. This correlation of vegetarian diet with vitamin $\mathrm{D}$ deficiency is found statistically significant $(\mathrm{p}<0.001)$.

Table 2: Distribution of cases according to sunscreen lotion/ cream uses.

\begin{tabular}{|c|c|c|c|c|}
\hline \multirow{2}{*}{ Sunscreen } & \multicolumn{3}{|c|}{ Vitamin D } & \\
\hline & $<30 \mathrm{ng} / \mathrm{ml}$ & $\geq 30 \mathrm{ng} / \mathrm{ml}$ & Total & \\
\hline Yes & $65(94.5 \%)$ & $4(21.05 \%)$ & $69(57.5 \%)$ & Chi square value $=12.27$ \\
\hline No & $36(70.59 \%)$ & $15(78.95 \%)$ & $51(42.5 \%)$ & $\mathrm{DF}=1 \mathrm{P}=0.00046 \mathrm{HS}$ \\
\hline Total & $101(100 \%)$ & $19(100 \%)$ & $120(100 \%)$ & \\
\hline
\end{tabular}

$69(57.75 \%)$ patients used sunscreen lotion/cream out of this $65(94.5 \%)$ patients were found vitamin D deficient and $4(21.05 \%)$ were vitamin D sufficient.51 (42.5\%) patients were not used sunscreen lotion/cream out of this $36(70.59 \%)$ patients were found vitamin D deficient and $15(78.95 \%)$ were vitamin D sufficient. This association between vitamin D deficiency and uses of sunscreen lotion/cream found to be statistically significant $(p<0.05)$.

Maximum 49 (40.83\%) patient's first visit was in 28-36 weeks of gestational age. Minimum $6(5 \%)$ patient's first visit was in first trimester $(<12$ week). Majority of patients, $84(70 \%)$ were belonged to primipara, out of this $71(84.52 \%)$ found vitamin D deficient and $13(15.48 \%)$ were vitamin D sufficient.

Rest 36 (30\%) were multipara. Out of this 30 (25\%) were vitamin D deficient and $8(31.5 \%)$ were vitamin D sufficient.
Table 3: Distribution of cases according to development of preeclampsia.

\begin{tabular}{|l|l|lll|}
\hline PE & $\begin{array}{l}\text { Vit D } \\
\text { deficient }\end{array}$ & $\begin{array}{l}\text { Vit D } \\
\text { sufficient }\end{array}$ & Total & P value \\
\hline \multirow{2}{*}{ Yes } & $\begin{array}{l}26 \\
(78.8 \%)\end{array}$ & $\begin{array}{l}07 \\
(21.1 \%)\end{array}$ & $\begin{array}{l}33 \\
(27.5 \%)\end{array}$ & $\begin{array}{l}\text { Chi square } \\
\text { value=22.52 }\end{array}$ \\
\hline \multirow{2}{*}{ No } & 25 & 62 & 87 & DF=1 \\
& $(28.7 \%)$ & $(71.2 \%)$ & $(72.5 \%)$ & P<0.0001 HS \\
\hline \multirow{2}{*}{ Total } & $\begin{array}{l}51 \\
(42.5 \% \mathrm{~s})\end{array}$ & $\begin{array}{l}69 \\
(57.5 \%)\end{array}$ & $\begin{array}{l}120 \\
(100 \%)\end{array}$ \\
\hline
\end{tabular}

In a population of 120 antenatal patients $33(27.5 \%)$ patients developed preeclampsia and rest $87(72.5 \%)$ patients were normotensive. Out of 33 patients of preeclampsia $26(78.8 \%)$ were vitamin D deficient and only $7(21.21 \%)$ were vitamin D sufficient. 
Total 69 patients were vitamin D sufficient out of this only $7(10.1 \%)$ patient developed preeclampsia and 62(89.8\%) were normotensive. This correlation between vitamin D deficient and sufficient patients with preeclampsia found statistically significant $(\mathrm{p}<0.001)$. In the study of 120 patients only $2(1.6 \%)$ patients developed GDM out of which one was vitamin D sufficient and another one was vitamin D deficient. As number of cases who developed GDM was only 2 and majority $(98.01 \%)$ of patients were euglycemics.

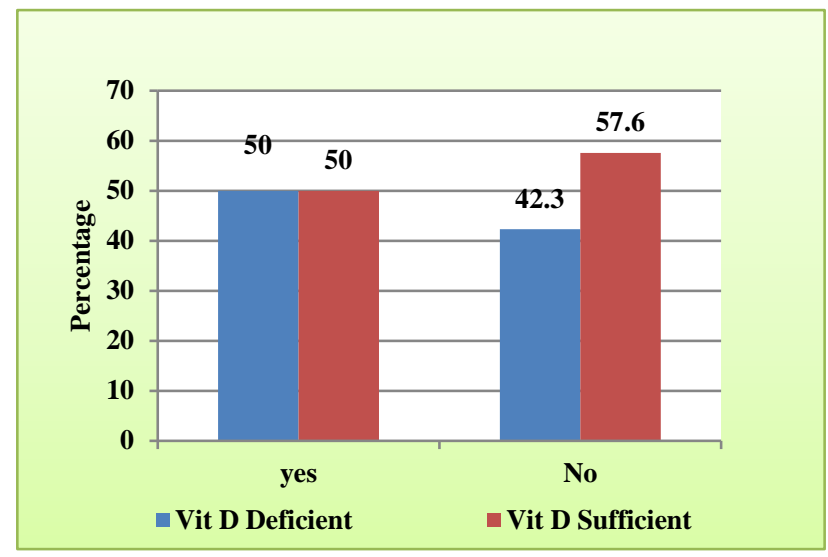

Figure 2: Distribution of case according to development of gestation diabetes mellitus.

Total of $60(50 \%)$ patients delivered by LSCS, out of this $23(38.3 \%)$ were vitamin D deficient and 37 (61.66\%). 60
(50\%) patients delivered normal vaginally, out of this 28 (46.6\%) were vitamin D deficient and 32 (53.3\%) were vitamin D sufficient This association was statistically not significant $(\mathrm{p}>0.4)$.

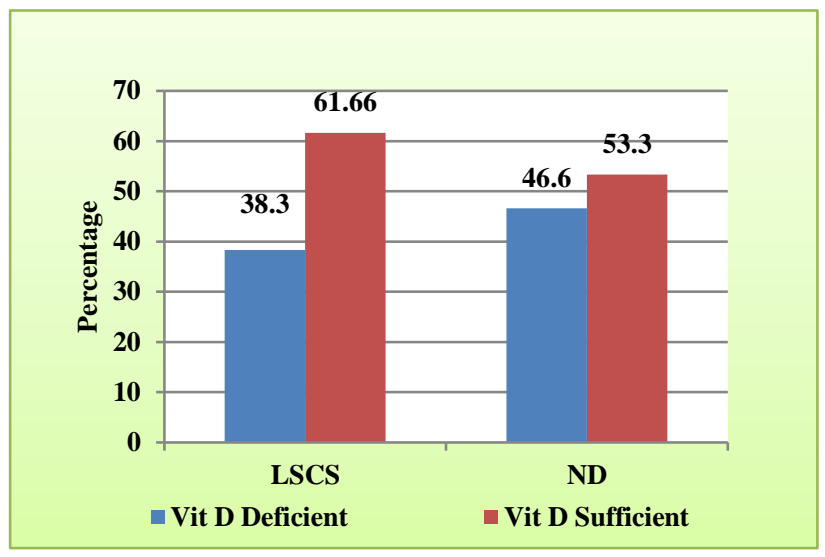

Figure 3: Distribution of cases according to mode of delivery.

In the study of 120 patients 108 (90\%) patients delivered at term and $12(10 \%)$ patients gave birth to preterm baby. Out of 108 mothers who delivered term baby, 41 (37.96\%) were vitamin D deficient and 67 (62.03\%) were vitamin D sufficient. Out of 12 mothers of preterm baby, $10(83.3 \%)$ were vitamin D deficient and only $2(16.37 \%)$ were vitamin $\mathrm{D}$ sufficient. This correlation was found to be significant $(\mathrm{P}<0.01)$.

Table 4: Distribution of cases according to period of gestation.

\begin{tabular}{|lllll|}
\hline POG & Vit D deficient & Vit D sufficient & Total & P value \\
\hline Preterm & $10(83.33 \%)$ & $2(16.37 \%)$ & $12(10 \%)$ & Chi square value=7.335 \\
\hline Term & $41(37.96 \%)$ & $67(62.03 \%)$ & $108(90 \%)$ & DF=1 P=0.007 HS \\
\hline Total & $51(42.5 \%)$ & $69(57.5 \%)$ & $120(100 \%)$ & \\
\hline
\end{tabular}

Table 5: Distribution of cases according to birth weight of new born.

\begin{tabular}{|lllll|}
\hline Birth weight & Vit D deficient & Vit D sufficient & Total & P value \\
\hline$\leq 2.5 \mathrm{~kg}$ & $27(77.14 \%)$ & $8(22.8 \%)$ & $35(29.1 \%)$ & Chi square value=22.306 \\
\hline$>2.5 \mathrm{~kg}$ & $24(35.41 \%)$ & $61(71.1 \%)$ & $85(70.08 \%)$ & DF=1 P<0.01 Significant \\
\hline Total & $51(42.5 \%)$ & $69(57.5 \%)$ & $120(100 \%)$ & \\
\hline
\end{tabular}

$35(29.1 \%)$ patients delivered low birth weight babies, out of this $27(77.14 \%)$ were vitamin D deficient and only $8(22.8 \%)$ were vitamin D sufficient. $85(70.08 \%)$ had normal birth weight babies, out of this 24 (35.41\%) were vitamin D deficient and $61(71.1 \%)$ were vitamin D sufficient. This correlation between vitamin D deficient and vitamin D sufficient patients with birth weight of babies found statistically significant $(\mathrm{p}<0.01)$.

\section{DISCUSSION}

It has been estimated that 1 billion people worldwide, across all ethical and age group, have vitamin D deficiency and insufficiency. There is widespread prevalence of varying degree ranging from 36-94\% involving all age group both sexes and pregnant women. Vitamin D deficiency is also not uncommon in India in 
spite of receiving ample sunlight throughout the year. ${ }^{10-12}$ Vitamin D deficiency in Indian pregnant women ranging from $42-93 \% .^{13-16}$

The present study was undertaken in order to determine the vitamin D level in 120 pregnant women on their first visit to hospital irrespective of their gestational age. In present study the prevalence of vitamin D deficiency was $84.1 \%$ or 841.66 per thousand women. Similarly, prevalence of vitamin D deficiency in pregnant women reported by Jani $\mathrm{R}$ et al, Sachan A et al and Dasgupta et al, Chauhan R et al was $100 \%, 84.3 \%$ and $42 \%, 72.1 \%$ respectively. ${ }^{11,13,14,26}$ In present study, age range was 19 39 years. Vitamin D deficiency was found most common in $25-29$ years $(51.67 \%)$ with mean age $28.31 \pm 3.86$ years.

Johnson D et al conducted study on 310 pregnant women and also found mean age 24.3 (range 18-40 year) of vitamin D deficient patients. ${ }^{27}$ Mallah et al conducted a study in Jordanians at national level revealed that women who wear hijab or niqab were more likely to have low levels vitamin D. ${ }^{28}$ In present study of 120 patients, $114(95 \%)$ cases were Hindu; out of this $97(85 \%)$ had vitamin D deficiency. Only $6(5 \%)$ cases were Muslim out of which $4(66.66 \%)$ had vitamin D deficiency. In present study out of $81(67.5 \%)$ vegetarian patients, 75 (92.59\%) were vitamin D deficient.

Out of $39(32.5 \%)$ non-vegetarian, 26 (66.6\%) were vitamin D deficient. Hence, vitamin D deficiency was more pronounce in vegetarian compare to nonvegetarian. This association between vitamin $D$ deficiency and diet was found to be statistically significant $(\mathrm{p}<0.005)$. Similarly, Crowel et al found that plasma $25(\mathrm{OH}) \mathrm{D}$ concentration were lower in vegetarian than meat and fish eater. ${ }^{29}$ In present study patients who used sunscreen cream/lotion, $94.2 \%$ were vitamin D deficient and on other hand $51(42.5 \%)$ patients who were not used sunscreen cream vitamin D deficiency observed in $36(70.56 \%)$ patients.

Thus, cases who used sunscreen cream are more prone to developed vitamin D deficiency than who do not. This association with sunscreen cream found statistically significant $(\mathrm{p}<0.05)$. Holick MF et al in 1977 also found that the most important source of vitamin D is skin's synthesis of vitamin D from sunlight and use of sunblock and time spend indoor increases the risk of vitamin D deficiency. ${ }^{22}$

In the present study of 120 antenatal patients, $33(27.5 \%)$ patients developed preeclampsia and rest $87(72.5 \%)$ patients were normotensive. Out of 33 patients of preeclampsia, 26 (78.8\%) were vitamin D deficient. Total 69 patients had vitamin D level in sufficient range, which included 19 patients having vitamin $\mathrm{D}$ in normal range on first visit and 50 patients who were supplemented with 8 weeks of vitamin D in early pregnancy to normalise their vitamin D level. Amongst these 69 patients, only 7 $(10.1 \%)$ patients developed preeclampsia. This correlation between vitamin D deficient and sufficient patients with preeclampsia found statistically significant $(p<0.001)$. Thus, vitamin D deficiency has been observed to be a factor for development of preeclampsia and supplementation with vitamin D for minimum of 8 weeks likely to reduce risk of preeclampsia

Similarly, Bodnar et al in 2007, Baker et al in 2010, Robinson et al in 2011 and Chauhan R in 2015 also found that prevalence of vitamin $\mathrm{D}$ deficiency is more prevalent in preeclamptic women. ${ }^{19,26,30,31}$ As Malbanan and Goswami reported successful normalization of serum $25(\mathrm{OH}) \mathrm{D}$ at 8 weeks after supplementing with $60,000 \mathrm{IU}$ orally cholecalciferol each week to vitamin D deficient patients. $^{24,25}$ Similarly, in present study authors have supplemented all vitamin D deficient patients with 60,000 IU weekly. These patients who can be supplemented with 8 weeks of weekly vitamin D were considered as vitamin $\mathrm{D}$ sufficient and rest where therapy was given in late pregnancy ( $<8$ weeks) were considered as vitamin D deficient.

According to the studies done by Marya et al, Emadi et al and Taheri $\mathrm{M}$ et al vitamin $\mathrm{D}$ supplementation associated with significant reduction in the risk of preeclampsia. ${ }^{32-34}$ Similarly, in present study out of 69 patients of vitamin D sufficient level only 7 patients developed preeclampsia, thus there may be a possible association of vitamin D supplementation and reduced risk of pre-eclamsia.

In present study out of 120 patients only 2 developed gestational diabetes mellitus, 99 patients were euglycemic. The number is too less to draw any conclusion about association. In present study LSCS was done in 60 patients, out of which 23(38.3\%) were vitamin $\mathrm{D}$ deficient and $37(61.66 \%)$ were vitamin $\mathrm{D}$ sufficient. Out of normal vaginal delivery patients (60/120), 28 (46.6\%) were vitamin D deficient and 32 (53.3\%) were vitamin D sufficient.

Dror DK et al in 2011 also found no change in mean vitamin D level between women who underwent caesarean delivery and who did not. ${ }^{35}$ Contrary to this Merewood et al in 2008 found that women with low vitamin $\mathrm{D}$ level had four times the odds of caesarean delivery. ${ }^{28}$ In present study maximum 108 (90\%) out of 120 patients delivered at term and Only $12(10 \%)$ patients had preterm delivery. Out of 108 mother who delivered term baby, 67 (62.03\%) were vitamin D sufficient and 41 $(37.96 \%)$ were vitamin $\mathrm{D}$ deficient. 12 mothers of preterm baby,10 $(83.3 \%)$ were vitamin $\mathrm{D}$ deficient and only $2(16.2 \%)$ were vitamin D deficient. Wagner et al in 2013 that supplemented 257 pregnant women for 12-16 week of gestational age with vitamin D (2000 IU) found risk reduction in preterm infection and preterm birth. ${ }^{36}$

In the present study of 120 patients a total of 35 patients had low birth weight babies out of this $77.14 \%$ (27) were vitamin D deficient and only 8 patients $(22.6 \%)$ patients were vitamin D sufficient. Total of 69 vitamin D 
sufficient patients only $8(11.5 \%)$ delivered low birth weight babies. Here the $\mathrm{p}$ value for low birth weight patients was statistically significant $(\mathrm{p}<0.05)$.

Thus, vitamin $\mathrm{D}$ deficiency has been observed to be linked with low birth weight newborns and vitamin D supplementation may reduce the risk of supplementation. Similarly, Brook et al in 1980 also reported reduced incidence of low birth weight babies in vitamin D supplement Asian mother. ${ }^{37}$

\section{CONCLUSION}

Vitamin D deficiency has high prevalence in Indian pregnant women and investigation during first trimester to diagnose deficient patients and timely supplementation during pregnancy can significantly reduce the chance of preeclampsia and low birth weight babies.

Funding: No funding sources

Conflict of interest: None declared

Ethical approval: The study was approved by the Institutional Ethics Committee

\section{REFERENCES}

1. Holick MF, Chen TC. Vitamin D deficiency: A worldwide problem with health consequences. Am J Clin Nutr. 2008;87:S1080-6.

2. Van der wielen RP, Lowik MR, Van den berg H, De Groot LC, Haller J, Moreiras O, et al. Serum vitamin $\mathrm{D}$ concentration among elderly people in Europe. Lancet. 1995;346:207-10.

3. Pilz S, Dobnig H, Tomaschitz A, Kienreich K, Meinitzer A, Friedl C, et al. Low 25-hydroxyvitamin $\mathrm{D}$ is associated with increased mortality in female nursing home residents. J Clin Endocrinol Metab. 2012;97(4):E653-7.

4. Ardawi MSM, Sibiany AM, Bakhsh TM, Qari MH, Maimani AA. High prevalence of vitamin D deficiency among healthy Saudi Arabian men: relationship to bone mineral density, parathyroid hormone, bone turnover markers, and lifestyle factors. Osteoporos Int J Establ Result Coop Eur Found Osteoporos Natl Osteoporos Found USA. 2012;23(2):675-86.

5. Karim SA, Nusrat U, Aziz S. Vitamin D deficiency in pregnant women and their newborns as seen at a tertiary-care center in Karachi, Pakistan. Int $\mathbf{J}$ Gynaecol Obstet Off Organ Int Fed Gynaecol Obstet. 2011;112(1):59-62.

6. Tao M, Shao H, Gu J, Zhen Z. Vitamin D status of pregnant women in Shanghai, China. J Matern-Fetal Neonatal Med Off J Eur Assoc Perinat Med Fed Asia Ocean Perinat Soc Int Soc Perinat Obstet. 2012;25(3):237-9.

7. Shibata M, Suzuki A, Sekiya T, Sekiguchi S, Asano S, Udagawa Y, et al. High prevalence of hypovitaminosis $\mathrm{D}$ in pregnant Japanese women with threatened premature delivery. J Bone Miner Metab. 2011;29(5):615-20.

8. Harinarayan CV, Joshi SR. Vitamin D status in India--its implications and remedial measures. J Assoc Physicians India. 2009;57:40-8.

9. Marwaha RK, Sripathy G. Vitamin D and bone mineral density of healthy school children in northern India. Indian J Med Res. 2008;127(3):239.

10. Tandon VR, Sharma S, Mahajan S, Raina K, Mahajan A, Khajuria V, et al. Prevalence of vitamin $\mathrm{d}$ deficiency among Indian menopausal women and its correlation with diabetes: A first Indian cross sectional data. J Life Health. 2014;5(3):121-5.

11. Jani R, Palekar S, Munipally T, Ghugre P, Udipi S. Widespread 25-hydroxyvitamin $\mathrm{D}$ deficiency in affluent and nonaffluent pregnant Indian women. Bio Med Res Int. 2014;2014:892162.

12. Sahu M, Bhatia V, Aggarwal A, Rawat V, Saxena P, Pandey A, et al. Vitamin D deficiency in rural girls and pregnant women despite abundant sunshine in northern India. Clin Endocrinol (Oxf). 2009;70(5):680-4.

13. Sachan A, Gupta R, Das V, Agarwal A, Awasthi PK, Bhatia V. High prevalence of vitamin D deficiency among pregnant women and their newborns in northern India. Am J Clin Nutr. 2005;81(5):1060-4.

14. Dasgupta A, Saikia U, Sarma D. Status of $25(\mathrm{OH}) \mathrm{D}$ levels in pregnancy: A study from the North Eastern part of India. Indian $\mathrm{J}$ Endocrinol Metab. 2012;16(Suppl2):S405-7.

15. Bikle D. Non-classic actions of vitamin D. J Clin Endocrinol Metab. 2009;94(1):26-34.

16. Mizwicki MT, Norman AW. The vitamin D sterolvitamin $\mathrm{D}$ receptor ensemble model offers unique insights into both genomic and rapid-response signaling. Sci Signal. 2009;2(75):re4.

17. Bodnar LM, Catov JM, Simhan HN, Holick MF, Powers RW, Roberts JM. Maternal vitamin D deficiency increases the risk of preeclampsia. J Clin Endocrinol Metab. 2007;92(9):3517-22.

18. Mannion CA, Gray-Donald K, Koski KG. Association of low intake of milk and vitamin D during pregnancy with decreased birth weight. CMAJ Can Med Assoc J. 2006;174(9):1273-7.

19. Zhang C, Qiu C, Hu FB, David RM, van Dam RM, Bralley A, et al. Maternal plasma 25-hydroxyvitamin $\mathrm{D}$ concentrations and the risk for gestational diabetes mellitus. PloS One. 2008;3(11):e3753.

20. Merewood A, Mehta SD, Chen TC, Bauchner H, Holick MF. Association between vitamin D deficiency and primary cesarean section. J Clin Endocrinol Metab. 2009;94(3):940-5.

21. DeLuca HF. History of the discovery of vitamin D and its active metabolites. BoneKEy Rep. 2014;3:479.

22. Holick MF, Frommer JE, McNeill SC, Richtand NM, Henley JW, Potts JT. Photometabolism of 7dehydrocholesterol to previtamin D3 in skin. Biochem Biophys Res Commun. 1977;76(1):107-14. 
23. Institute of medicine (IOM). Dietary reference intake for calcium, phosphorus, magnesium, vitamin D and fluoride. Washington (DC): National Academis; 2011.

24. Malabanan A, Veronikis IE, Holick MF. Redefining vitamin D insufficiency. Lancet Lond Engl. 1998;351(9105):805-6.

25. Goswami R, Gupta N, Ray D, Singh N, Tomar N. Pattern of 25-hydroxy vitamin D response at short (2 month) and long (1 year) interval after 8 weeks of oral supplementation with cholecalciferol in Asian Indians with chronic hypovitaminosis $\mathrm{D} \mathrm{Br} \mathrm{J}$ Nutr. 2008;100(3):526-9.

26. Chauhan R, Chauhan M, Baghel P. Prevelance of vitamin $\mathrm{D}$ deficiency and it's outcome in pregnancy at tertiary center. Int J Med Sci. 2015;4suppl 1(23203137):170-7.

27. Johnson DD, Wagner CL, Hulsey TC, McNeil RB, Ebeling M, Hollis BW. Vitamin D deficiency and insufficiency is common during pregnancy. Am J Perinatol. 2011;28(1):7-12.

28. Mallah EM, Hamad MF, Elmanaseer MA, Qinna NA, Idkaidek NM, Arafat TA, et al. Plasma concentrations of 25-hydroxyvitamin D among Jordanians: Effect of biological and habitual factors on vitamin D status. BMC Clin Pathol. 2011;11:8.

29. Crowe FL, Steur M, Allen NE, Appleby PN, Travis RC, Key TJ. Plasma concentrations of 25hydroxyvitamin $\mathrm{D}$ in meat eaters, fish eaters, vegetarians and vegans: results from the EPIC? Oxford study. Public Health Nutr. 2011;14(2):340-6.

30. Baker AM, Haeri S, Camargo CA, Espinola JA, Stuebe AM. A nested case-control study of midgestation vitamin D deficiency and risk of severe preeclampsia. J Clin Endocrinol Metab. 2010;95(11):5105-9.

31. Robinson CJ, Wagner CL, Hollis BW, Baatz JE, Johnson DD. Maternal vitamin D and fetal growth in early-onset severe preeclampsia. Am J Obstet Gynecol. 2011;204(6):556.e1-4.

32. Marya RK, Rathee S, Manrow M. Effect of calcium and vitamin D supplementation on toxaemia of pregnancy. Gynecol Obstet Invest. 1987;24(1):38-42.

33. Emadi SA, Hammoudeh M. Vitamin D study in pregnant women and their babies. Research Gate. 2013;2013(1):32-7.

34. Taheri M, Baheiraei A, Rahimi Foroushani A, Modarres M. Resolving vitamin D deficiency in the preconception period among high-risk reproductive women: a randomized controlled trial. Iran Red Crescent Med J. 2014;16(1).

35. Dror DK, King JC, Durand DJ, Allen LH. Association of modifiable and nonmodifiable factors with vitamin $\mathrm{D}$ status in pregnant women and neonates in Oakland. CA J Am Diet Assoc. 2011;111(1):111-6.

36. Wagner CL, McNeil R, Hamilton SA, Winkler J, Cook CR, Warner G, et al. A randomized trial of vitamin $\mathrm{D}$ supplementation in 2 community health center networks in South Carolina. Am J Obstet Gynecol. 2013;208(2):137.e1-137.e13

37. Brooke OG, Brown IR, Bone CD, Carter ND, Cleeve HJ, Maxwell JD, et al. Vitamin D supplements in pregnant Asian women: effects on calcium status and fetal growth. Br Med J. 1980;280(6216):751-4.

Cite this article as: Yadav M, Verma MK, Bairwa M, Meena G, Rajoria L. Prevalence of vitamin D deficiency and effect of vitamin D supplementation on feto-maternal outcome in tertiary care centre. Int $\mathbf{J}$ Reprod Contracept Obstet Gynecol 2018;7:4912-8. 